\title{
RESOCIALIZACIÓN EN POLONIA
}

\author{
Resocialization in Poland
}

Johana Graywa-Holten *

Resumen: El texto describe el desarrollo de la rehabilitación en Polonia. Muestra, por un lado, los énfasis para su integración en la sociedad, tanto como las distintas discusiones respecto de la rehabilitación; y, por otro, los problemas de implementación de la sanción o medida.

Palabras clave: rehabilitación de condenados - privación de libertad - ejecución de condenas en Polonia.

Abstract: The paper describes the development of the rehabilitation in Poland showing, on the one hand, the legal emphasis for social reintegration as well as the different discussions about rehabilitation as a penalty's aim and, on the other hand, the issue of imprisonment sanctions enforcement or its measure.

Keybord: rehabilitation of offenders - deprivation of liberty - imprisonment enforcement in Poland.

\section{Ley de ejecución de sanciones privativas de libertad en Polonia}

La pregunta sobre el fin de la ejecución de la sanción privativa de libertad es compleja y de varias dimensiones. Incluso dentro de las ciencias, la política y en la totalidad de la sociedad el debate es acalorado y las opiniones se separan marcadamente. La complejidad del tema se reflejó no solo en el trabajo de codificación de los años 90, sino que también en la actual Ley de Ejecución de Sanciones Penales, donde volvió a debatirse sobre el fin que ha de tener la sanción privativa de libertad. La discusión se centró en el distinto rol o protagonismo que deberían tener, en el momento de la ejecución de la sanción penal, las clásicas teorías sobre el fin de la pena, como en los diferentes modelos de aprendizaje, tratamiento y las variadas perspectivas criminológicas, pedagógicas y sociológicas.

Según el artículo 67 párrafo 1 de la Ley de Ejecución polaca, el objetivo de la ejecución debe ser: preparar al condenado para que, a través de educación civica y otras medidas efectivas, le permitan respetar los derechos de los terceros, lograr un sentimiento de responsabilidad y llevar una vida futura sin delitos.

\footnotetext{
*Abogada, doctora en Derecho por la Universidad Ernst-Moritz-Arndt-Greifswald de Alemania. Investigadora del Centro de Criminología y Derecho Penal de la misma Universidad. Traducción Dr. Álvaro Castro Morales. Correo electrónico: grzywa@uni-greifswald.de

Este artículo fue recibido el 16 de febrero de 2015, siendo aprobada su publicación el26 de junio de 2015.
} 
Una importante diferencia en comparación con la legislación de 1969 es la renuncia a una resocialización obligatoria. En vez de la imposición de las medidas prevalece en la actualidad la estimulación y animación que se movilizan en un proceso abierto que debe contribuir al regreso del condenado a la sociedad con las herramientas que le permitan retomar una vida libre de delitos. ${ }^{1}$ En concreto, el cambio de actitud debe provenir de la voluntad interna del condenado y por ello las medidas y programas deben ser entendidos como ofertas que el privado de libertad puede aceptar o rechazar.

Con esa finalidad deben ser considerados dos aspectos: por una parte el derecho de cada persona a autodeterminarse y con ello el respeto de su dignidad humana, que le permite elegir libremente si quiere o no modificar su vida. El segundo aspecto es de naturaleza pragmática. El factor clave en el proceso de resocialización consiste en que la decisión de cambio haya sido tomada por el propio privado de libertad. La imposición de las normas de conductas tiene poca eficacia cuando se trata de lograr conductas conformes al derecho. La prolongada adhesión al derecho puede darse solamente con el trabajo conjunto, voluntario, entre el sujeto motivado libremente y el educador. ${ }^{2}$ Por ello el razonamiento de la Ley de Ejecución polaca, expresado en sus fundamentos, es el siguiente: el rechazo de la resocialización obligatoria en el periodo en que se ejecuta la condena se funda en el reconocimiento de los derechos humanos, de la decisión libre, como de una comprensión realista del estado de las cosas, para que las medidas que se imponen a las personas sean efectivas, deben ser aceptadas libremente por ellas. ${ }^{3}$

El legislador polaco se ha decidido, a diferencia del legislador alemán, a regular separadamente los conceptos de "fin" y de "tarea". El fin de la ejecución de sanciones penales, según el legislador polaco, es el de la resocialización y la tarea que debe perseguirse con la ejecución consiste en la protección de la comunidad. Esta tarea es en el artículo 73 parágrafo 1 explicada de la siguiente forma: En los centros penitenciarios debe mantenerse la disciplina y el orden para salvaguardar la seguridad y realización de la tarea de la pena privativa de libertad consistente en proteger a la comunidad de

\footnotetext{
1 La obligatoriedad de las medidas resocializadoras, agrupadas bajo el "sistema de efecto programado", se aplicaban a todos los privados de libertad con excepción de los adolescentes y jóvenes adultos hasta los 21 años.

2 Véase ŚLIWOWSKI (1981), p. 182.

${ }^{3}$ Fundamentación del proyecto de ley sobre ejecución de las sanciones penales de 1997, p. 25.

${ }^{4}$ La reforma Federal de 2006 entrega a los estados federales alemanes la competencia sobre los temas de ejecución de sanciones penales y con ello la obligación de dictar leyes de ejecución. En este contexto en HESSEN, BAYERN, BADEN-WÜRTTEMBERG y NIEDERSACHSE tiene la resocialización y la protección de la sociedad el mismo rango. Véase DüNKEL (2004), p. 17. Esta tendencia también puede observarse en diferentes países europeos, véase PRATT (2002) y ZALEWSKI (2006). Sin embargo los otros estados federales alemanes le han dado prioridad al fin de la resocialización, véase el proyecto conjunto de ley de los 10 estados federales de 23.8.2011, en www. http://beck-

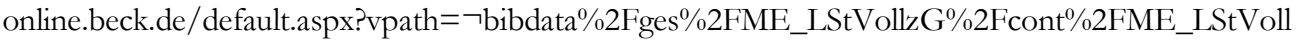
zG\%2EP3\%2Ehtm; en el caso de las leyes de ejecución de la sanción privativa de libertad juvenil véase OSTENDORF(2012).
} 
la criminalidad. La diferencia legal entre fin y tarea no ha sido pacífica en la doctrina nacional. Un sector de ella es de la opinión que esta tarea debe ser considerada como un fin de la sanción privativa de libertad. Esta opinión es de larga data y fue desarrollada por la Corte Suprema polaca a finales de los sesenta. En la misma línea, otras opiniones consideran inaceptable no ponderar en la etapa de ejecución los fines que fueron determinantes en la etapa de determinación de la sanción penal. Con ello podrían perfectamente concurrir en la etapa de la ejecución de la pena privativa de libertad los objetivos preventivo generales y de retribución.

Sin embargo, es cuestionable que esta jurisprudencia pueda ser mantenida con la legislación vigente $\mathrm{y}^{5}$ aún con los estándares internacionales que rechazan en la etapa de ejecución la pluralidad de fines. ${ }^{6}$ La Ley de Ejecución vigente formula de forma clara y expresa la existencia de un solo fin en la ejecución de la pena privativa de libertad. Se trata de la prevención individual (prevención especial). La consideración de los otros fines de la pena deben tener cabida en otras dimensiones del sistema de justicia criminal, por ejemplo, la prevención general puede tener un rol preponderante en la etapa legislativa buscando con la amenaza penal desmotivar conductas contrarias al derecho o en la etapa de determinación judicial de la pena. ${ }^{7}$

Mas para una sociedad que aspira a la realización de los derechos humanos, no solo en un sentido político, sino que también económico, sería difícil mantener este propósito si en los recintos penitenciarios la prevención general e, incluso, la retribución dominaran las decisiones administrativas. La decisión de cómo vamos a utilizar y organizar esta dimensión del sistema de justicia debe quedar supeditada a otros criterios. Por ello debemos leer el artículo 67 de la Ley de Ejecución de forma tal que en la etapa de ejecución solo se deje espacio para las medidas que busquen lograr cambios de conducta en el privado de libertad que le permitan una reincorporación libre de delitos a la sociedad.

La protección de la sociedad como tarea se logra con el aislamiento en un recinto penitenciario, esto es con la expulsión del condenado de la sociedad, bajo esquemas de disciplina y respeto del derecho. Esta tarea debe estar siempre limitada y considerando los derechos de los privados de libertad. No debemos olvidar los principios europeos para la ejecución de sanciones penales, los que claramente ordenan que la pena privativa de libertad solo debe limitar el derecho al desplazamiento. ${ }^{8}$

\footnotetext{
${ }^{5}$ Véase Holda/POSTUlSKI (1998), p. 214.

${ }^{6}$ Vid. Principios europeos para la sanción privativa de libertad, Reglas Nr. 102 y 102.2.

${ }^{7}$ Holda / POSTULSKI (1998), p. 216.

8 Regla Nr. 102.1 y 102.2 de los Principios sobre la ejecución de las sanciones penales europea.Sobre el fin y tarea de la ejecución de sanciones penales juveniles desde una perspectiva de los estándares internacionales, véase KÜHL (2012), pp. 41 ss.
} 
El concepto de los fines es, en comparación con las tareas, más variado y de gran alcance. El fin debe estar presente en la totalidad de las medidas que son aplicadas al condenado y en las decisiones que le afectan durante su estadía en un centro penitenciario. Dicho de otra manera, todos los tratamientos que recaen en el privado de libertad, así como las decisiones que a él alcanzan, deberían estar sujetas al fin. La ejecución de la pena privativa de libertad, no cabe duda, será siempre reconocida como el aislamiento del individuo, sin embargo no se debe olvidar que con él hay importantes aspectos de contenido (programas o decisiones) que deberían ser llenados desde una perspectiva preventiva individual positiva. ${ }^{9}$

Tampoco debe olvidarse que la prevención individual sirve de la mejor manera a la protección general de la comunidad. No se trata solo del interés del privado de libertad, sino además del interés de la sociedad toda. En la medida en que el privado de libertad luego de la puesta en libertad no cometa más delitos $-\mathrm{y}$ avanzando un poco más- interiorice las reglas de la vida en común, se estará protegiendo de la mejor manera los intereses de toda la sociedad. Por ello resulta determinante no olvidar que, en algún momento, el recluido saldrá en libertad y que su desenvolvimiento en la comunidad, si se motiva o no conforme a las normas desarrollando la voluntad y capacidades que lo habilitan a seguir los principios de la vida en común, dependerá en gran medida del apoyo recibido durante (y después) de su estadía en la cárcel, ${ }^{10}$ cuestión que está directamente relacionada con los intereses generales de la comunidad.

Esta idea en torno a la cual se afirma que el logro de la prevención especial positiva materializa de la mejor manera la protección de la comunidad, ha sido recogida por el Tribunal Federal alemán. ${ }^{11}$ En la jurisprudencia del tribunal alemán se desarrollan tres argumentos por los que es necesario preparar de forma efectiva a los infractores para su regreso en el medio libre: el privado de libertad es portador de la dignidad humana, y dicha dignidad le otorga el derecho a regresar a la comunidad después de haber cumplido con su condena. Además el principio de un Estado social obligaría a brindar apoyo a los grupos que se encuentren en desventaja social sea por debilidad o incapacidad. Y qué duda cabe los privados de libertad, como los egresados del sistema penitenciario (los puestos en libertad) pertenecen a este grupo. Por último, y no por ello menos importante, no se debe olvidar que la resocialización se encuentra al servicio de la protección de la comunidad en general, directamente cuando el infractor no reincide y no daña a los ciudadanos. ${ }^{12}$

\footnotetext{
${ }^{9}$ CioseK (2008), p. 330. También en la ejecución penal alemana CALLIES / MÜLLER-DiETZ (2008), \2, Rn 1-3; FEeST / LESTING (2012), \2, Rz 3-15.

10 Véase FEeST / LeSTING (2012), \ 2 Comentarios previos p. 21. También LeLENTAL (2010b), p. 869.

${ }^{11}$ El tribunal constitucional federal alemán (BVverfGE) ha desarrollado esta idea no solo para los adultos sino también para los adolescentes privados de libertad en su fallo de mayo de 2006, véase BVerfG, 2 BvR 1673/04 de 31.5.2006.

12 Fallo del BVerfGE 35, p. 202 ss.
} 


\section{Resocialización y reincorporación en la sociedad (readaptación)}

El concepto de resocialización y de readaptación social aparece mencionado en diversas partes de la ley como en otros cuerpos normativos del ordenamiento jurídico polaco. En los hechos, el artículo 67 de la Ley de Ejecución polaca no define ni da cuenta de ninguna terminología concreta que permita entender el proceso interior de cambio de actitud del sujeto. En el artículo 38 de la misma ley, a propósito de la participación de los clubes, fundaciones y organizaciones vinculadas con la ejecución de la sanción penal de condenados y sujetos a prisión preventiva, se exige para participar en los recintos carcelarios no solo la autorización del director del centro, sino además la ejecución de actividades que tengan un efecto social, resocializador, cultural y espiritual.

También en la justificación de la Ley de Ejecución se encuentra la expresión "reinserción". ${ }^{13}$ Igualmente es mencionada en otro cuerpo normativo la ley que regula la libertad condicional, a propósito de la lista de tareas de os delegados de libertad condicional, en el primer lugar la tarea educadoraresocializadora. En iguales términos introduce el artículo 2 de la Ley Orgánica de la Ejecución de Sanciones Penales: la ejecución de medidas resocializadoras para los condenados a la pena privativa de libertad.

La expresión "readaptación social" es, a su turno, introducida en el título del Capítulo 7 de la Ley de Ejecución de la siguiente manera: La participación de la sociedad en la ejecución de la condena: la ayuda para la readaptación social del condenado, la puesta en libertady la ayuda a la víctima.

Si nos preguntamos acerca de cuál es el fin de la sanción privativa de libertad en Polonia, debemos responder sin lugar a dudas, que es el preventivo especial y que, al igual que en la literatura científica internacional, una de las expresiones más usadas para materializar este fin es el de "resocialización". Igualmente se utilizan con la misma intensidad el concepto de "rehabilitación", "reintegración social" o "reincorporación a la sociedad". ${ }^{14}$ Con todo debemos advertir que resulta difícil diferenciar, definir y jerarquizar estos conceptos, puesto que ellos provienen de diferentes culturas legales, con dispares desarrollos de las ciencias sociales y donde las traducciones hacen que la comprensión en torno a las nomenclaturas varíe de lugar en lugar. ${ }^{15}$

\footnotetext{
${ }^{13}$ Fundamentación del proyecto de ley sobre Ejecución de sanciones penales de 1997, p. 544 ss.

${ }^{14}$ FeEst / Lesting (2012), \2 2, Comentarios previos p. 5; Cornel (2009), pp. 34 ss.

15 Es muy difícil traducir las definiciones contenidas en los conceptos legales, ya que ellos están inmersos dentro de un sistema jurídico y cubiertos de un lenguaje técnico que imposibilita desprender una traducción precisa acerca de ese concepto que contenga el alcance y sentido que dicho sistema le otorga. Por ejemplo en Polonia la resocialización como concepto se desarrolla desde la pedagogía "pedagogía penitenciaria" y comprende la preparación, realización, evaluación
} 
En Polonia, no obstante las variadas investigaciones y publicaciones sobre el tema de la resocialización y sus variadas nomenclaturas, no existe una única definición aceptada. Frecuentemente no se habla de la resocialización en sí misma, sino de la pedagogía resocializadora, proceso resocializador, educación resocializadora, método resocializador, paradigma resocializador y sobre los principios axiológicos, psicológicos, sociales y criminológicos de la resocialización. ${ }^{16}$

El concepto de resocialización, en Polonia, es discutido en el marco de la pedagogía diferenciada y se alude a ella en términos generales como pedagogía de la resocialización. ${ }^{17}$ Esta disciplina busca mediante el trabajo levantar elementos educativos y enseñanzas que sean útiles para las personas que son "descarriadas sociales". En otras palabras, una disciplina que busca tratar las conductas divergentes con actividades laborales, en las que se busca intervenir al privado de libertad con métodos psicológicos, criminológicos, sociológicos y si son necesarios, médicos. ${ }^{18}$ Lo que se busca es lograr con ello un aprendizaje interdisciplinario. ${ }^{19}$ Sin embargo, en el último tiempo se ha abierto en la discusión científica una perspectiva más pragmática que busca desarrollar programas educativos basados solamente en el nivel de peligro del privado de libertad y trabajar a partir de un cálculo de riesgo y no con métodos más integrales.

También se ha discutido sobre el rol del derecho en este caso y se ha llegado al consenso de que a este le toca determinar con claridad cuál será la amplitud de las medidas resocializadoras y fiscalizar eventuales vulneraciones de derechos acaecidas durante la aplicación de las mismas.

Los precursores en Polonia de la pedagogía de la resocialización son Czapówy Jedlecki ${ }^{20} \mathrm{y}$ gracias al trabajo de estos expertos se construyó el pensamiento resocializador en el país. Con todo, a lo largo del tiempo otros autores desde diversas orientaciones, disciplinas y perspectivas han enriquecido el debate sobre el concepto de reinserción. Veamos los más importantes.

de todas las medidas de carácter educativo, terapéutico, cultural, recreacional como laborales que se aplican a los privados de libertad, véase SzCZEPANIAK (2013a), p. 173. También en la literatura alemana el concepto de resocialización tiene varias facetas. Para Laubenthal la resocialización comprende la suma de todos los esfuerzos desplegados en la etapa de ejecución que buscan que el privado de libertad, por medio de una capacitación, pueda vivir con responsabilidad social y sin cometer delitos. Maelicke considera que la resocialización forma parte del proceso de socialización que se lleva a cabo dentro de la prisión, véase CORNEL (2009), p. 46.

${ }^{16}$ MAJCHERCZYK (2013), p. 135.

17 La pedagogía de la resocialización se desarrolla en Polonia durante el siglo XX y ha sido enriquecida por diferentes disciplinas: psicología, criminología y sociología. Véase KONOPCZYŃSKI (2008), p. 203.

${ }^{18}$ KONOPCZYŃSKI (2008), p. 203 ss.

${ }^{19} \mathrm{Vgl}$. STAŃDO-KAWECKA (2000), p. 12.

20 Czapów y Jedlecki publicaron en 1971 el primer libro sobre Resocialización bajo el título Pedagogikaresocjalizacyjna/-Resoz̨ialisierungspädagogik, véase. PYTKA (2008), p. 95. 
Según Czapów la pedagogía de la resocialización debe buscar el aprendizaje interdisciplinario, comprendiendo tres dimensiones: axiológica, teórica y práctica ${ }^{21}$ y centrarse en tres escenarios: cuidado, enseñanza y terapia. ${ }^{22}$

Pytka ha destacado lo difícil que ha sido en esta disciplina establecer teorías unitarias o definiciones marco que sean aplicables a todos los casos, ya que siempre la individualidad del sujeto obligaría a desarrollar medidas resocializadoras para cada caso. Por ello, podría la resocialización actuar de diferentes formas, donde lo único claro sería lo que se busca, por ejemplo, modificar conductas, cambiar las emociones, familiarizarse con la cultura de la satisfacción de las necesidades, adecuarse a las situaciones sociales, a la comprensión y respeto de los principios y valores sociales. ${ }^{23}$

Konopczyncki diferencia cuatro conceptos de resocialización: el conductual, el interactivo, el interdisciplinario y el cognitivo. El primero busca adecuar las conductas refractarias con las formas de conductas socialmente permitidas. Este concepto se basa en las teorías de la enseñanza. El segundo se centra en las relaciones interpersonales y los papeles que cada una de las personas debe ejecutar en la sociedad. El tercer concepto se vincula con las teorías del control social, en especial con los diferentes modelos de asociación (teoría de los contactos diferenciales) que se basa en las teorías integrativas de las conductas criminales de Le Blanc. Y el último concepto se basa en las teorías cognitivas de G. Kelly. ${ }^{24}$

Pospieszyl vincula la resocialización con la psicología. Según él no se puede hablar de una corriente o escuela determinada, sino más bien de tres direcciones psicológicas, las que buscan no solo cambiar las conductas criminales, sino además desarrollar una específica visión del proceso de resocialización. ${ }^{25}$ Estas direcciones son: resocialización como canalización de los instintos, ${ }^{26}$ psicoanálisis (como forma de resolver los problemas internos) y el conductualismo (resocialización como forma de aprendizaje de conductas y costumbres). ${ }^{27}$

Opora introduce en Polonia la corriente del comportamiento cognoscitivo, el que se centra en los fundamentos de la aceptación como un proceso interno del pensamiento que permite corregir el comportamiento externo fallido y con ello la adecuación de la conducta con los requisitos exigidos por la sociedad. ${ }^{28}$

\footnotetext{
21 PYTKA (2008), p. 95.

22 Ibid., p. 96.

${ }^{23}$ Ibid., pp. 73 ss.

${ }^{24}$ KONOPCZYŃSKI (2008), pp. 205-208.

25 PosPiesZYL (2008), p. 77 ss.

26 Área de la psicología que estudia las motivaciones y aspectos dinámicos del comportamiento humano.

27 POSPIESZYL (2008), pp. 77 ss.

${ }^{28}$ OPORA (2010), pp. 15 ss.
} 
En Machel podemos encontrar una definición del proceso de resocialización de corte legal o que se basa en las normas de la ley de ejecución. El proceso de resocialización en la etapa de ejecución significa una orientada corrección conductual llevada a cabo por la administración del recinto, previo diagnóstico y plan de tratamiento, centrada en el trabajo conjunto con diferentes instituciones fuera del centro y cuyo fin es lograr un cambio de actitud y llevar en el futuro una vida libre de delitos.

Jaworska pone énfasis en las condiciones del encierro, en los aspectos que deben guiar la reinserción dentro de una cárcel. Según el autor, la ejecución de la sanción debe generar en algún momento un efecto humanista que satisfaga una serie de paradigmas: el paradigma del aprendizaje, de la autorrealización, de sobreponerse a la rutina, del respeto a la dignidad y de la prevención de la estigmatización. $^{29}$

Aunque estos autores ponen énfasis en diferentes aspectos, orientaciones y disciplinas para referirse a la reinserción, es claro que en términos generales ella es formulada como un proceso de socialización secundario, ${ }^{30}$ de reincorporación de personas en las que el proceso de socialización es defectuoso o fracasó. ${ }^{31}$ Con ello "reinserción" comprenderá toda medida que tenga un carácter educativo o terapéutico y que tenga por objeto lograr que el sujeto vuelva a la comunidad y se represente una vida sin delito. ${ }^{32}$

También la resocialización ha sido vista como un proceso de cambio o como de "readaptación" social, es decir, es visto por muchos autores como resultado o "estado final". ${ }^{33} \mathrm{El}$ proceso de resocialización comprende dos dimensiones: el subjetivo o psicológico, que tiene lugar como proceso de cambio interno y la dimensión objetiva que tiene lugar en el cambio externo de la conducta, en el actuar observable. Dimensiones que cuando se concretan darán origen, según Szalanski, a una readaptación psicológico-social que se caracteriza por la propia aceptación del cambio interior y la conformidad del comportamiento con las normas sociales. ${ }^{34} \mathrm{Sin}$ embargo, esta perspectiva no ha estado exenta de críticas, por ejemplo, para Obuchowski la adaptación como resultado de gestiones resocializadoras es algo muy complejo e idealista, ya que la adaptación se basa en una autorrealización por medio del logro de los ideales humanos, única forma de mantener la individualidad y el desarrollo propio en armonía con la integración social. ${ }^{35}$

\footnotetext{
${ }^{29}$ JAWORSKA(2009), p. 137 ss.

${ }^{30}$ El concepto de socialización es discutido en la literatura, existen diferentes teorías y por ello resulta difícil utilizarlo en el campo de la resocialización. Véase WALKENHORST (2011), pp. 71 ss.

${ }^{31}$ STAŃDO-KAWECKA (2000), p. 11.

${ }^{32}$ MAJCHERCZYK (2006), p. 16.

33 Véase SZAŁAŃSKI (2008b), p. 16; HoŁDA / POSTULSKI (2005), p. 311.

${ }^{34}$ SZAŁAŃSKI (2008b), p. 17.

35 Ibid., p. 14.
} 
En virtud de la difícil concretización de las perspectivas mencionadas más atrás Machel manifestó la necesidad de aterrizar el concepto de resocialización y ofrecer un mínimo que pudiera llevarse a cabo dentro de los centros cerrados. Ese mínimo, según Machel, debería ser la mejoría política, esto es la no vulneración de las normas penales. La idea es generar un cambio en la personalidad del preso que le permita, después de la puesta en libertad, funcionar en sociedad no lesionando normas y con ello protegiendo al individuo y a la sociedad, ya que se está evitando la reincidencia. La mejoría política sería la conformidad de la conducta con la norma y tendría lugar cuando se alcanza en el sujeto la conformidad, la voluntad que gira en no cometer más delitos siendo irrelevante si está o no de acuerdo con los valores de la sociedad. Da lo mismo si cree o no en la norma, lo importante es que la respete; que sea para el derecho un ser inofensivo.

El concepto de mejoría política ha sido criticado por los pedagogos. Ellos consideran que no es suficiente y lo han tildado de superficial, ya que la no comisión de un delito por parte de un preso puesto en libertad puede verse como un cambio, pero que no asegura una profunda internalización de las normas sociales. Además generaría una protección de la sociedad de corto alcance puesto que la disconformidad con las normas terminará tarde o temprano gatillando la vulneración de las mismas. De ahí que no podría hablarse de una "reincorporación" en un sentido humanístico, sino se aceptan interiormente los más importantes valores sociales y se contribuye comprometidamente con una vida en sociedad.

Más allá del alcance que debería tener la resocialización Obuchowski estima que en esta debería primar solo un paradigma: considerar al preso como persona, un sujeto de derecho y no un objeto que es utilizado durante el proceso de resocialización y obligado a adherir a los estilos de vida imperantes en su comunidad. En este sentido, según Obuchowski, los programas rehabilitadores deben reflejar la categoría de lo posible, de lo pensable, realizable. Debería la resocialización ser entendida más como una pretensión, la que para ser exitosa debe tener una representación ideal del cambio de actitud con sentido creativo, humano y eficiente. ${ }^{36}$

\footnotetext{
${ }^{36}$ MACHEL (2003), p. 21.
} 


\section{Práctica y efectividad de los programas ejecutados en los centros privativos de libertad polacos}

Después de la Segunda Guerra Mundial comienza en Polonia, producto del dominio comunista, una discusión sobre la resocialización y la efectividad de las medidas resocializadoras. Con el cambio del sistema político las medidas resocializadoras fueron en gran medida politizadas y sirvieron como medio por el cual se enseñaba la ideología socialista. La generación de un debate políticocriminal y el desarrollo de evidencia empírica fueron posibles ${ }^{37}$ solo en la segunda mitad de la década del cincuenta. Un positivo papel en el desarrollo del debate jugó el trabajo conjunto entre los especialistas y el Ministerio de Justicia, como también la aprobación de los Principios mínimos para el tratamiento de los privados de libertad de las Naciones Unidas. ${ }^{38}$ Bajo este nuevo impulso fueron desarrollados programas de tratamiento que estaban acompañados por las ciencias sociales. El tema central de los nuevos avances consistió en la enseñanza por medio del trabajo, una mejor clasificación de los presos y la reforma de la ejecución de la pena privativa de libertad juvenil.

Resulta interesante el impacto que tuvieron en Polonia las nuevas discusiones que estaban teniendo lugar fuera del país en torno a la resocialización. $\mathrm{Si}$ bien es cierto los autores de la época conocieron las discusiones políticocriminales realizadas en torno a las sanciones alternativas a la pena privativa de libertad, los debates extranjeros referentes a programas específicos de tratamiento, el funcionamiento general de los centros penitenciarios de Europa del oeste y la decepción en Estados Unidos caracterizada por el "nada funciona". En la práctica, el servicio de prisiones se mantuvo escéptico frente a estos movimientos y corrientes y les otorgó poco valor. Estas nuevas tendencias eran consideradas ideologías del mundo capitalista que cuestionaban el fin de la rehabilitación que hasta ese momento era considerada en el país como un buen instrumento a favor de la divulgación socialista, ya que el fin de la resocialización se focalizaba en el "mejoramiento político", es decir, el autor resocializado era el ciudadano que desplegaba una vida al servicio del Estado socialista.

Hoy la resocialización goza en Polonia de un gran interés científico y prevalece la idea en torno a su complejidad, escasa evaluación y dificultad en llevarla a cabo. ${ }^{39}$ Con relación a la efectividad de la resocialización y las condiciones por las que se quiere materializar, existe escepticismo y resignación en el país. ${ }^{40} \mathrm{Si}$ bien los expertos valoran y promueven los estudios empíricos cualitativos para medir la efectividad de la resocialización, en la práctica las

\footnotetext{
${ }^{37}$ MAJCHERCZYK (2006), p. 18.

38 WALKENHORST(2011), p. 73.

${ }^{39}$ GÓRnY (1988), p. 588.

40 Los Principios mínimos fueron traducidos oficialmente al polaco en 1958, véase GÓRNY (1988), p. 590.
} 
investigaciones han sido más bien descriptivas, ${ }^{41}$ lo que hace difícil evaluar la efectividad y sustentabilidad de las medidas resocializadoras. ${ }^{42}$ Con todo se puede destacar el trabajo que desde la academia y la práctica se ha desplegado en torno a la identificación de factores criminológicos y su posterior tratamiento. ${ }^{43}$ Estos trabajos forman parte del renovado interés que en los últimos años han manifestado los especialistas en torno a lo "que sí funciona en la práctica" y la necesaria creación de medidores que permitan evaluar los programas. Este renovado interés ha sido provocado por la influencia que han tenido en el país las investigaciones anglosajonas, las que han introducido herramientas como el "principio de tratamiento efectivo" o el "tratamiento en base a riesgos". Sobre esto último merecen especial atención los trabajos de Andrews y Bonta con su modelo de Risk-Needs-Responsivity Model for Offender Assessment and Rebabilitation, el que se focaliza en las variables sociales, familiares y características individuales que podrían influir en la conducta criminal. ${ }^{44}$ De acuerdo con este modelo el tratamiento penitenciario debe considerar los siguientes aspectos o principios que buscan desarrollar las competencias o habilidades que los privados de libertad no poseen: el principio de riesgo (risk principle)busca determinar qué intensidad deberá tener la intervención sobre la base de los niveles de riesgo de reincidencia del condenado desarrollados con instrumentos especiales (ofender risk assessment instruments); ${ }^{45}$ el principio de necesidad (criminogenic needs principle) centra su mirada en la distinción de riesgos que están directamente vinculados con la conducta criminal de aquellos que no son determinantes; y el principio de responsabilidad (responsivity principle) busca adecuar la intervención a las características del preso para asegurar el éxito del mismo. ${ }^{46}$

Gracias a la influencia de la literatura anglosajona se ha logrado entender, por lo menos desde la teoría, la importancia de que los programas o tratamientos sean presentados con duración, fines e instrumentos determinados y que sean estructurados en etapas para su realización. También la importancia de una cuidadosa y planeada administración de las etapas, una estrategia de

\footnotetext{
${ }^{41}$ Szczypiorno o también en Gdańsk-Przeróbce - véase MACHEL (2004), p. 188.

42 Véase SZAŁAŃSKI (2008), p. 21; STAŃDO-KAWECKA (2010), pp. 113 ss.

${ }^{43} \mathrm{La}$ reincidencia oscila en Polonia entre 40\% y 50\%. Véase URBAN (2008), S. 313. Machel postula que hay que ser prudentes con la evaluación de la efectividad de las medidas y programas. Para tener una evaluación exacta se necesitan indicadores precisos de todos los factores que influyen el proceso de resocialización. Véase MACHEL(2011), pp. 172 ss, también. DüNKEL/DrENKHAHN (2001), S. 391y MORGENSTERN (2011).

44 Véase, BARTKOWICZ (2008), p. 27 f; SAKOWICZ (2008), p. 30; STAŃDO-KAWECKA (2010), p. 114.

${ }^{45}$ Véase Palmer(1975); Gendreau / Roos (1989); McGuire / Priestley (1995), p. 6; MCGuire(2004-2013) y en especial SHERMAN (1998); LÖSEL (1994-2012); DÜNKEL (2000); DünKel / DrenkHAHn (2001); EGG (2001). Para el tema "what works" y "evidence-based practice" en el sistema de libertad condicional inglés, véase BURNETT / ROBERTS (2004), pp. 4 ss. En el caso de la terapia social en Alemania véase DüNKEL (1983), pp. 44 ss.; DrENKHAHN (2007). Referente a la efectividad de la terapia de los autores de delitos sexuales, véase WisCHKA (2001); HOLLWEG / LIWON (2005) y WISCHKA (2009).

${ }^{46}$ BARTKOWICZ(2008), p. 27.
} 
implementación, ejecución, marco de condiciones institucionales, personales, una administración del riesgo y también monitoreo y evaluación. ${ }^{47}$ Esto último sería clave para saber qué es lo que está funcionando y qué puede ser replicado o copiado por otros recintos como un ejemplo digno de seguir. ${ }^{48}$ Por lo tanto, hoy nadie discute en Polonia, por lo menos desde el punto de vista teórico, que los programas de resocialización deben basarse en una consistente fundamentación teórica como también en información empírica. Tampoco que los programas de tratamiento deben orientarse en torno a las causas del comportamiento criminal y ejecutarse en pos del logro de transformaciones de las actitudes antisociales.

El problema que ha debido enfrentar este nuevo enfoque y que ha dificultado su implementación en el país es el de la escasez de recursos y la baja valoración social que se les otorga a estas innovaciones. Durante muchos años los recintos penitenciarios han ejecutado programas intensivos para drogodependientes, ${ }^{49}$ programas de antiagresión, de construcción de competencias sociales y de oficios y siempre han contado con las mismas limitaciones: jamás la sociedad los ha tenido en alta estima, su ejecución está inmersa en una compleja red burocrática y pocas veces los recursos han permitido su aplicación continuada y apropiada para un grupo considerable de privados de libertad. ${ }^{50}$ Lo anterior permite explicar la escasa fundamentación teórica que en la práctica han tenido los programas, la deficiente evaluación, el insuficiente personal (educadores, psicólogos) y precaria infraestructura. ${ }^{51}$ Sobre este último aspecto Majerczyk explica la paradójica situación en que trabajan los funcionarios penitenciarios: "los educadores hacen de todo, no solo aquello que deben hacer, deben tener tiempo para todo, pero menos para la resocialización". ${ }^{52}$

El problema de la escasez de personal y recursos no es solo un problema de Polonia. También en Alemania se ha hablado de estas deficiencias, por ejemplo, Walkenhorst destaca los siguientes núcleos problemáticos: por un lado no hay suficientes ofertas, educadores y los recursos de los programas no son duraderos. Por otro, el acompañamiento educativo no es llevado a cabo por el mejor personal y las instituciones encargadas de efectuarlo presentan serias deficiencias para trabajar con otras instituciones. En este escenario se hace difícil darles a los privados de libertad una oportunidad para que puedan cambiar su vida, o dicho en

\footnotetext{
47 Estas ideas han sido desarrolladas por MacKenzie en el conocido Sherman-Report: "The important issue is not whether something works but what works for whom”. Véase también DÜNKEL / DRENKHAHN (2001), p. 394.

48 ANDREws / BONTA /HOGE (1990). También ANDREWs / BONTA (2007), p. 4; BONTA / WORMTH (2013), pp. 72 ss.

49 MAJCHERCZYK (2006), p. 15; MARCZAK / PAWEXEK (2009), p. 334.; STAŃDO-KAWECKA (2010), p. 117.

${ }^{50}$ MAJCHERCZYK (2013) p. 199 ss;

51 Para una descripción de un buen modelo práctico implementado en el sistema de prisiones polaco, véase MARCZAK / PAWEłEK (2009); y en el caso del sistema alemán véase DüNKEL / DRENKHAHN / MORGENSTERN (2008), pp. 226 ss.

${ }^{52}$ De acuerdo con el sistema de ejecución polaco las personas que son alcoholdependientes deben ser internados en los sistemas terapéuticos para ser tratados.
} 
otras palabras, casi imposible lograr el fin del sistema: educar a los jóvenes y tratar a los adultos. ${ }^{53}$

La pregunta sobre la efectividad de las medidas de resocialización tampoco debe dejar de lado las condiciones de vida y las relaciones que dominan fuera de la cárcel. Aunque las limitaciones presentadas en los programas ejecutados intramuros se replican a los programas del pospenitenciario debemos ser categóricos en la relevancia que tiene esta etapa, la que en Polonia ha sido olvidada. Un exitoso programa de resocialización puede ser afectado por las escasas condiciones y oportunidades que tiene un exconvicto puesto en libertad. La falta de trabajo, vivienda, redes sociales incrementan las posibilidades de reincidencia y dificultan la permanencia de los positivos cambios en la personalidad del exprivado de libertad llevados a cabo dentro de la prisión. La resocialización debe entenderse como un proceso, como un desarrollo progresivo que no se entiende terminado cuando el privado de libertad sale de la cárcel. El apoyo debe continuar después de la puesta en libertad y para ello la sociedad debe calcular los costos de las medidas resocializadoras y la administración penitenciaria tener presente este momento desde el primer día en que el condenado ingresa a la prisión. ${ }^{54}$

\section{Palabras finales}

En Polonia la resocialización ha logrado imponerse como fin en la ley vigente que regula la ejecución de las sanciones penales privativas de libertad. Bajo esta legislación la dignidad humana se levanta como un principio fundamental que prohíbe el carácter obligatorio de los programas y la adhesión a determinados valores políticos que, como en la época socialista, buscaban imponerse forzosamente al privado de libertad transformando a la cárcel como un medio de adoctrinamiento político.

La ley de ejecución de sanciones privativas de libertad actual le da a la seguridad y al orden un rol secundario. Si bien es cierto que existe una discusión de larga data en el país en torno al valor que estos intereses deberían tener dentro de la ejecución, una interpretación realizada bajo el alero de los principios europeos para la sanción privativa de libertad permitiría desprender que estos no tienen más que el carácter de tarea y no deberían ser elevados al rango de fines.

El desarrollo del contenido de la resocialización se ha producido bajo el alero de diversas disciplinas, lo que permite explicar la riqueza y complejidad que el concepto ha alcanzado en la actualidad. Con todo, esta misma complejidad ha obligado a la doctrina a buscar un contenido que sea posible de utilizar en la práctica acotando sus pretensiones.

\footnotetext{
${ }^{53}$ MARCZAK (2009).

54 Andrews y Bonta definen las necesidades criminológicas como los factores dinámicos que muestran una relación directa con la comisión del delito. Véase ANDREWs / BONTA (2007), p. 5.
} 
En el ámbito de la ejecución de la pena privativa de libertad la resocialización goza de gran interés científico. Se destaca su complejidad y escasa evaluación como su dificultad para ser llevada a cabo en la práctica. De ahí que los desafíos apunten hacia mejorar la fundamentación teórica de los programas, su seguimiento, evaluación y levantamiento de información estadística. Aspectos que para ser llevados a cabo requieren de mayores recursos, más y mejor personal, como una adecuada infraestructura.

Como se desprende de lo antes expuesto, los desafíos son enormes para el derecho de la ejecución de sanciones polaca. A la falta de recursos e infraestructura se suman las dificultades de una población penal más compleja y en permanente transformación. Han existido avances en torno al mayor énfasis que se le ha dado, dentro de la legislación penitenciaria, a la noción preventivo-especial positiva, que aunque con distintos nombres, da cuenta del interés del legislador en poner al privado de libertad y sus cambios de actitud en el centro de la ejecución.

El esfuerzo por entender la forma en cómo vamos a lograr esos cambios de actitud permiten explicar la nutrida discusión doctrinaria que se ha desarrollado en el país y que lentamente, influenciada por la doctrina anglosajona, ha dado cabida a cuestiones metodológicas básicas como la evaluación y utilización de información empírica. Solo falta seguir enfatizando la importancia de estas metodologías y lograr que los operadores comiencen a incorporarlas en sus rutinas para así poder afirmar, con evidencia empírica sobre la mesa, qué es lo que funciona en las cárceles polacas. 


\section{BIBLIOGRAFIA}

* Andrews, Don; Bonta, James (2007): Raport Risk-Need-Responsivity Model for Offender Assessment and Rehabilitation" von unterwww.publicsafety.gc. ca/res/cor/rep/_fl/Risk_Need_2007-06_e.pdf.

* Andrews, Don; Bonta, James; Hoge, Robert (1990): Classification for effective rehabilitation: Rediscovering psychology. Criminal Justice and Behavior, 17.

* BartKowicz, Zdzisław(2008): Skuteczna resocjalizacja w perspektywie aksjologicznej i pomiarowej. In: Bartkowicz, Z., Weggliński, A. (Hrsg.): Skuteczna resocjalizacja. Doświadczenia i propozycje. Lublin: Wydawnictwo Uniwersytetu Marii CurieSkłodowskiej.

* Bonta, James; Wormith, J. Stephen (2013): Applying the Risk-Need-Responsivity Principles to Offender Assessment. In: Craig, L. A., Dixon, L., Gannon, T. A. (Hrsg.): What Works in Offender Rehabilitation. An Evidence-Based Approach to Assessment and Treatment. Wiley-Blackwell Publising.

* Begründung des Entwurfs des Strafvollstreckungsgesetzbuches 1997.

* Burnett, Ros; Roberts, Colin (2004): The emergence and importance of evidence based practice in probation and youth justice. In: Burnett, R., Roberts, C. (Hrsg.): What Works in Probation and Youth Justice. Cullompton Dewon: Willan Publishing.

* Calliess, Rolf-Peter; Müller-Dietz, Heinz (2008): Strafvollzugsgesetz. Auflage XX. München: Verlag C.H. Beck.

* CioseK, Mieczysław (2008): Zakład karny jako instytucja resocjalizacyjna. In: Urban, B., Stanik, J., M. (Hrsg.): Resocjalizacja. Band I und II. Warszawa: Wydawnictwo Naukowe.

* Cornel, Heinz (2009): Zum Begriff der Resozialisierung. In: Cornel, H., KawamuraReindl, G., Maelicke, B., Sonnen B., R. (Hrsg.): Resozialisierung. Handbuch. 3. Auflage. Baden-Baden: Nomos Verlag.

* Drenkhahn, Kristin (2009): Langstrafenvollzug und Menschenrechte - Erste Ergebnisse eines internationalen Forschungsprojekts. Neue Kriminalpolitik 21.

* DünKEL, Frieder (2004): Gegenreform im Strafvollzug: Sicherheit als Vollzugsziel -eine Gesetzesinitiative aus Hessen. KrimPäd, 32, Nr. 43.

(2000): Resozialisierungsvollzug (erneut) auf dem Prüfstand. In: Jehle, J.-M.

(Hrsg.): Täterbehandlung und neue Sanktionsformen. Mönchengladbach: Forum Verlag Godesberg.

(1983): Die Geschichte des Strafvollzuges als Geschichte von (vergeblichen?) Vollzugsreformen. In: Driebold, R. (Hrsg.): Strafvollzug. Erfahrungen, Modelle, Alternativen. Göttingen: Verlag Vandenhoeck \& Ruprecht.Drenkhahn 2007.

* DünKel, Frieder; DrenkHAHN, Kirstin (2001): Behandlung im Strafvollzug: von "nothing works" zu "something works". In: Bereswill, M., Greve, W. (Hrsg.): Forschungsthema Strafvollzug. Baden-Baden: Nomos.

* Dünkel, Frieder; Drenkhahn, Kristin; Morgenstern, Christine (2008): Praxismodelle zur Humanisierung des Strafvollzugs - eine Nachbetrachtung. In: Dünkel, F., Drenkhahn, K., Morgenstern, C. (Hrsg.): Humanisierung des Strafvollzugs - Konzepte und Praxismodelle. Mönchengladbach: Forum Verlag Godesberg.

* Feest, Johannes; Lesting, Wolfgang (Hrsg.) (2012): Kommentar zum Strafvollzugsgesetz. 6. Aufl. Köln: Carl Heymanns Verlag.

* Gorny, J.Slask (1988): Rozwój badań penitencjarnych. In: Wierzbicki, P. (Hrsg.): Rozwój penitencjarystyki w PRL. Wybrane problemy. Warszawa: Wydawnictwo Prawnicze.

* Holda, Zbigniew (1998): Kodeks karny wykonawczy. Komentarz.Gdańsk: Wydawnictwo Stella Maris. (2005): Kodeks Karny Wykonawczy. Komentarz. Gdańsk: Wydawnictwo Arche. 
* Hollweg, Mortiz; Liwon, Norbert (2005): Forschungsbedarf, internationale Forschung und methodische Probleme bei Forschungsvorhaben zur Behandlung von Sexualstraftäter. In: Wischka, B. u. a. (Hrsg.): Sozialtherapie im Justizvollzug. Lingen: Kriminalpädagogischer Verlag Lingen.

* Jaworska, Anetta (2009): Paradygmatyczne podstawy współczesnej resocjalizacji penitencjarnej. In: Jaworska, A. (Hrsg.): Resocjalizacja. Kraków: Oficyna Wydawnicza Impuls.

* KONOPCZYŃSKI, Marec (2008): Współczesne nurty resocjalizacji. In: Urban, B.,Stanik, J. M. (Hrsg.): Resocjalizacja. Band I und II. Warszawa: Wydawnictwo Naukowe.

* KüHL, Johannes (2012): Die gesetzliche Reform des Jugendstrafvollzuges in Deutschland im Licht der European Rules for Juvenile Offenders Subject to Sanctions or Measures (ERJOSSM). Mönchengladbach: Forum Verlag Godesberg.

* Laubenthal, Klaus (2011): Strafvollzug. 6. Aufl. Berlin: Springer Verlag.

* Lelental, Stanislav (2010b): Cel wykonywania kary pozbawienia wolności oraz warunki i środki jego realizacji w świetle Art. 67 k.k.w. In: Konarska-Wrzosek, V., Lachowski, J., Wójcikiewicz, J. (Hrsg.): Węzłowe problemy prawa karnego, kriminologii i polityki kryminalnej. Warszawa: Lex a Wolters Kluwer.

* LÖSEL, Friedrich (1994): Meta-analytische Beiträge zur wiederbelebten Diskussion des Behandlungsgedankens. In: Steller, M. (Hrsg.): Straftäterbehandlung. Argumente für eine Revitalisierung in Forschung und Praxis. Herbolzheim: Centaurus.

(2012): Offender treatment and rehabilitation: What works? In: M. Maguire, M., Morgan R., Reiner, R. (Hrsg.): The Oxford handbook of criminology. Oxford, UK: Oxford University Press.5. Auflage.

* Machel, Henryk (2003): Więzienie jako instytcja karna i resocjalizacyjna. Gdańsk: Wydawnictowo Arche.

(2011): Niektóre czynniki wzmacniające skuteczność poprawczą więzienia. In: Kalisz, T. (Hrsg.): Prawo karne wykonawcze w systemie nauk kryminologicznych. Księga pamiątkowa ku czci Profesora Leszka Boguni.Wrocław: Wydawnictwo Uniwersytetu Wrocławskiego.

* MajCherczyK, Andrzej (2013): Projektowanie i implementacja programów resocjalizacji. In: Szczepaniak, P. (Hrsg.): Polski system penitencjarny. Ujęcie integralno-kulturowe. Warszawa: Wydawnictwo Forum Penitencjarne.

(2006):Programy resocjalizacji skazanych - głos w dyskusji o stanie i perspektywach więziennictwa. Przegląd Więziennictwa Polskiego, Nr. 52-53.

* Marczak, Monika; PaweŁeK, Katarzyna (2009): Od projektowania do ewaluacji: kilka słów o skuteczności programów realizowanych wobec osób pozbawionych wolności. In: Marczak, M. (Hrsg): Resocjalizacyjne programy penitencjarne realizowane przez służbę więzienną w Polsce. Kraków: Oficyna Wydawnicza Impuls.

* Martinson, Robert (1974): What Works? Questions and Answers About Prison Reform. The Public Interest, 35.

* McGuire, James (2013): "What works" to Reduce Re-Offending: 18 Years On. In: Craig, L. A., Dixon, L., Gannon, T. A. (Hrsg.): What works in Offender Rehabilitation. An Evidence-Based Approach to Assessment and Treatment. Wiley-Blackwell Publishing.

* McGuire, James; Priestley, Philip (1995): Reviewing "What works": Past, Present and Future. In: McGuire, J. (Hrsg.): What works: Reducing Reoffending. Chichester: Wiley.

* OpOra, Robert (2010): Resocjalizacja: wychowanie i psychokorekcja nieletnich niedostosowanych społecznie. Kraków: Impuls.

* Ostendorf, Heribert (2012): Jugendstrafvollzugsrecht. Kommentierende Darstellung der einzelnen Jugendstrafvollzugsgesetze. 2. Aufl., Baden-Baden: Nomos Verlag.

* Pospiszyl, Kazimierz (2008): Psychologiczne podstawy resocjalizacji. In: Urban, B., Stanik, J. M. (Hrsg.): Resocjalizacja. Warszawa: Wydawnictwo Naukowe PWN. 
* PratT, John (2002): Punishment \& Civilisation. London/Thousand Oaks/New Delhi: SAGE Publications.

* PytKa, Lesław (2008): Różne ujęcia definicji resocjalizacji. In: Urban, B., Stanik, J.M.(Hrsg.): Resocjalizacja. Warszawa: Wydawnictwo Naukowe PWN.

* SAkowicz, Tadeusz (2008): Zmierzch czy renesans zakładowej resocjalizacji. In: Barkowicz, Z., Węgliński, A. (Hrsg.): Skuteczna resocjalizacja. Lublin: Wydawnictwo Uniwersytetu Marii Curie-Skłodowskiej.

* Sherman, Laurence W. u. a. (1998): Preventing crime. What works, what doesn't, what's promising? U. S. Department of Justice, Office of Justice Programs, National Institute of Justice, Research in Brief. www.preventingcrime.org.

* Śliwowski, Jerzy (1981): Kara pozbawienia wolności we wspōłczesnym świecie.Rozważania penitencjarne i penologiczne. Warszawa: Wydawnictwo Prawnicze.

* Stańdo-Kawecka, Bárbara (2000): Prawne podstawy resocjalizacji 1. Aufl. Kraków.Pytka 2008.

* Szatański, Jan (2008a): Kategorie klasyfikacyjne i zróżnicowanie osobowościowe skazanych jako wyznaczniki celów i programów resocjalizacji penitencjarnej. In: Urban, B., Stanik, J. M. (Hrsg.): Resocjalizacja. Warszawa: Wydawnictwo Naukowe PWN. (2008b): Zakres i poziom skuteczności resocjalizacji. In: Z. Bartkowicz, Z., Węgliński, A. (Hrsg.): Skuteczna resocjalizacja. Doświadczenia i propozycje Lublin: Wydawnictwo UMCS.

* Walkenhorst, Philipp (2011): Marginalien zur Mitarbeiteraus- und Fortbildung für den Jugendvollzug. In: Stelly, W., Thomas, J. (Hrsg.): Erziehung und Strafe. Symposium zum 35-jährigen Bestehen der JVA Adelsheim. Mönchengladbach: Forum Verlag Godesberg. (2004): Auch Zuwendung ist eine Intervention. Interview. Dosier des Berufsbildungswerk Dr. Fritz Bauer Förderverein e. V.

* WischKA, Berndu. a. (2001): Das Behandlungsprogramm für Sexualstraftäter (BPS)in Niedersächsischen Justizvollzug. In: Rehn, G u. a. (Hrsg.): Behandlung „gefährlicher Straftäter". Grundlagen, Konzepte, Ergebnisse. Herbolzheim: Centaurus. (2009): Terapia sprawców przestępstw seksualnych w więziennictwieRepubliki Federalnej Niemiec. Przegląd Więziennictwa Polskiego 2009, Nr. 65. (2005): Sozialtherapie im Justizvollzug: Aktuelle Konzepte, Erfahrungen und Kooperationsmodelle. Lingen: Kriminalpädagogischer Verlag Lingen.

* ZaLewski, Wojciech (2006): Sprawiedliwość naprawcza. Gdańsk: Arche. 